\title{
Promotion of nucleopolyhedrovirus infection in larvae of the silkworm, Bombyx mori (Lepidoptera: Bombycidae) by an antibiotic, nikkomycin $\mathrm{Z}$
}

\author{
Toru Arakawa* and Masao Sugiyama ${ }^{1}$ \\ National Institute of Agrobiological Sciences (NIAS), Tsukuba, Ibaraki 305-8634, Japan \\ ${ }^{1}$ Biochemical Laboratory, Central Research Laboratories, Hokko Chemical Industry Co., Ltd., Atsugi, Kanagawa 243-0023, Japan \\ (Received 10 December 2001; Accepted 3 April 2002)
}

\begin{abstract}
Nikkomycin Z, an antibiotic, promoted infection of Bombyx mori nucleopolyhedrovirus (BmNPV) in 4th-stadium B. mori larvae, when the chemical was incorporated into the larval diet. The median lethal dose $\left(\mathrm{LD}_{50}\right)$ of $\mathrm{BmNPV}$ was decreased as the concentration of nikkomycin $Z$ was increased. $\mathrm{LD}_{50}$ of $\mathrm{BmNPV}$ in larvae that received $10 \mathrm{ppm}$ nikkomycin $Z$ was $0.7-1.1$ polyhedra/larva. The peritrophic membrane was not observed in the gut of larvae that had received $10 \mathrm{ppm}$ nikkomycin $\mathrm{Z}$. Although the growth of larvae that had received $10 \mathrm{ppm}$ nikkomycin $\mathrm{Z}$ was delayed, they molted to the next stadium.
\end{abstract}

Key words: Nikkomycin Z, chitin synthesis inhibitor, nucleopolyhedrovirus, Bombyx mori, microbial pesticide

\section{INTRODUCTION}

Insect viruses such as nucleopolyhedroviruses (NPVs) are promising candidates for pest controlling agents (Shieh, 1989), and several NPVs have been registered as microbial pesticides (see Okada, 1994). For commercial production of the virus, cost of the viral insect control must be competitive with that of existing chemical insect controls. The cost of producing a viral product using a large amount of hosts is high, hampering industrial production of viral pesticides. As a result, Sandoz discontinued virus production in 1983 (see Sato, 1985; see Shapiro and Vaughn, 1995).

There are many reports of chemicals that enhance viral infection (see Goto, 1999), which aim to reduce the viral dose that kills target insects; the goal is to require viral pesticide production on a smaller scale. Arakawa (2002) showed that the silkworm, Bombyx mori, ingesting acetone-dissolved flufenoxuron became sensitive to $B$. mori NPV (BmNPV). Flufenoxuron is an insect growth regulator (IGR) that inhibits epidermal chitin synthase, resulting in an inability to molt (Lee et al., 1990). Effectiveness of flufenoxuron suggests that chitin-related chemicals are candidates for an enhancer of viral infection. In the present paper, we report that a chitin synthesis inhibitor, nikkomycin
Z, promotes NPV infection in the silkworm, $B$. mori.

\section{MATERIALS AND METHODS}

Insects and virus. Silkworm larvae (Fuyoh $\times$ Tohkai) were reared similarly to the method described in Arakawa (2002). Aliquots from the same polyhedral suspension of BmNPV strain A 505 as had been used in Arakawa (2002) were used in this study, and contained $7.4 \times 10^{8}$ polyhedra $/ \mathrm{ml}$.

Chemicals. Nikkomycin $Z$, an antibiotic, purchased from Sigma Chemical Co., Ltd. was tested for the promotion of viral infection and was compared with the effect of flufenoxuron purchased from Wako Pure Chemical Industries Co., Ltd. These chemicals were administered perorally by incorporating them into the diet as follows. Nikkomycin $\mathrm{Z}$ was dissolved in $1 \mathrm{ml}$ distilled water and mixed with $19 \mathrm{~g}$ crushed Silkmate $2 \mathrm{~S}$ (Nihon Nohsan-Kogyo Co., Ltd.), an artificial diet. The mixture was kneaded well with a medical spurtle. Flufenoxuron was dissolved in $400 \mu \mathrm{l}$ acetone and mixed with $19 \mathrm{~g}$ crushed Silkmate $2 \mathrm{~S}$ and $600 \mu \mathrm{l}$ distilled water, and the mixture was kneaded well. This diet contained $2 \%$ acetone immediately after preparation. The final concentrations of nikkomycin $\mathrm{Z}$ and flufenoxuron were $1-100 \mathrm{ppm}$ and $10-100$

* To whom correspondence should be addressed at: E-mail: arak@nias.affrc.go.jp 
ppm, respectively. Control larvae received a similarly prepared diet without nikkomycin $\mathrm{Z}$ and flufenoxuron.

Bioassay for NPV susceptibility. The polyhedral suspension was serially diluted tenfold with distilled water and used for preparation of viral paste, which consisted of dried mulberry leaf powder $(0.1 \mathrm{~g}), 10 \%(\mathrm{w} / \mathrm{w})$ sucrose solution $(100 \mu \mathrm{l})$ and BmNPV polyhedral suspension $(150 \mu 1)$. This paste was kneaded well with a medical spurtle in a glass petri dish and divided into five parts $(0.07 \mathrm{~g})$ by using a balance. Each part was placed on wet filter paper in a plastic cup $(120 \mathrm{ml})$ and administered to a 4th-stadium B. mori larva. The viral paste was completely consumed in $24 \mathrm{~h}$ at $25^{\circ} \mathrm{C}$. Then the larva was supplied with $2.5 \mathrm{~g}$ Silkmate $2 \mathrm{~S}$. Larvae were reared until they died of viral infection or molted to the 5th stadium. The dead larvae were dissected and their degenerating tissue debris was observed with a microscope to detect viral polyhedra. Groups of five larvae were used to assay each viral dose. $\mathrm{LD}_{50}$ was calculated by the limiting-dilution value and the number of polyhedra in the viral paste using the Spearman-Karber method (Finney, 1964).

Dose effect of nikkomycin $Z$ and flufenoxuron. Newly ecdysed 4th-stadium silkworm larvae were fed a diet $(0.5 \mathrm{~g} /$ larva) containing nikkomycin $\mathrm{Z}$ or acetone-dissolved flufenoxuron. After $22 \mathrm{~h}$ of feeding, about $60-70 \%$ of the diet was consumed. Then the larvae were starved for $2 \mathrm{~h}$ and bioassayed for NPV susceptibility.

Observation of the peritrophic membrane. Ten newly ecdysed 4th-stadium silkworm larvae were fed a diet containing $10 \mathrm{ppm}$ nikkomycin $\mathrm{Z}$. After $22 \mathrm{~h}$ of feeding, the larvae were starved for $2 \mathrm{~h}$ and then dissected to expose their internal organs. Their alimentary canals were cut at a joint between the fore- and mid-guts. The peritrophic membrane was removed from their midguts with forceps and immersed in distilled water to observe with the naked eye.

Effect of nikkomycin $Z$ on the development of the silkworm. Newly ecdysed 3rd- and 4th-stadium silkworm larvae were left with Silkmate $2 \mathrm{~S}$ containing nikkomycin $\mathrm{Z}$ at $10 \mathrm{ppm}$. Then, they were transferred to a normal diet without nikkomycin $\mathrm{Z}$ and reared until they developed to the next stadium. The duration during which they were left with nikkomycin Z-containing diet is shown in Table 3. Groups of 10 larvae each were used to assay each duration of the nikkomycin $Z$ diet. The developmental stage was checked once a day. Days required to develop to the next stadium were analyzed by the Mann-Whitney $U$-test based on the duration of the nikkomycin $\mathrm{Z}$ diet.

\section{RESULTS}

\section{Dose effect of nikkomycin $Z$ and flufenoxuron}

When the larvae were fed a diet containing nikkomycin $\mathrm{Z}$ at $1,3,10$ and $100 \mathrm{ppm}$, the $\mathrm{LD}_{50} \mathrm{~s}$ were $2.8 \times 10^{5}-2.8 \times 10^{6}, 1.1-7.0 \times 10^{1}, 0.7-1.1 \times$ $10^{0}$ and $0.4-1.1 \times 10^{0}$ polyhedra/larva, respectively (Table 1). The $\mathrm{LD}_{50}$ of control larvae was $1.8-4.4 \times 10^{6}$ polyhedra/larva or more. The results indicated that the NPV-susceptibility was increased as the concentration of nikkomycin $\mathrm{Z}$ in the diet was increased in a range from 1 to $10 \mathrm{ppm}$. The effect of nikkomycin $Z$ was assumed to be maximal at $10 \mathrm{ppm}$ because the same degree of infectious enhancement was obtained at 10 and $100 \mathrm{ppm}$. No larvae that did not receive NPV polyhedra died of viral infection (data not shown).

\section{Dose effect of flufenoxuron}

When 4th-stadium silkworm larvae were fed diet containing acetone-dissolved flufenoxuron at 10 and $100 \mathrm{ppm}$, the $\mathrm{LD}_{50} \mathrm{~s}$ were $4.4-7.0 \times 10^{5}$ and $1.1 \times 10^{0}$, respectively (Table 2 ). The $\mathrm{LD}_{50}$ of control larvae was $1.8-2.8 \times 10^{6}$. Acetone-dissolved flufenoxuron scarcely promoted NPV infection at $10 \mathrm{ppm}$. The results are similar to those obtained for 5th-stadium silkworm larvae by Arakawa (2002). Larvae that had not received NPV polyhedra did not die of viral infection (data not shown).

\section{Peritrophic membrane of nikkomycin Z-treated larvae}

Fourth stadium silkworm larvae that had ingested $10 \mathrm{ppm}$ nikkomycin $\mathrm{Z}$ in the diet were dissected. The gut was filled with the diet ingested by the larvae, and the peritrophic membrane was not observed. In the control larvae that ingested a diet without nikkomycin $\mathrm{Z}$, the tubular peritrophic membrane of surrounding the ingested diet was observed and could be removed from the gut with forceps and immersed in distilled water. The membrane of the control larvae was so tough that it retained its tubular form in the distilled water. 

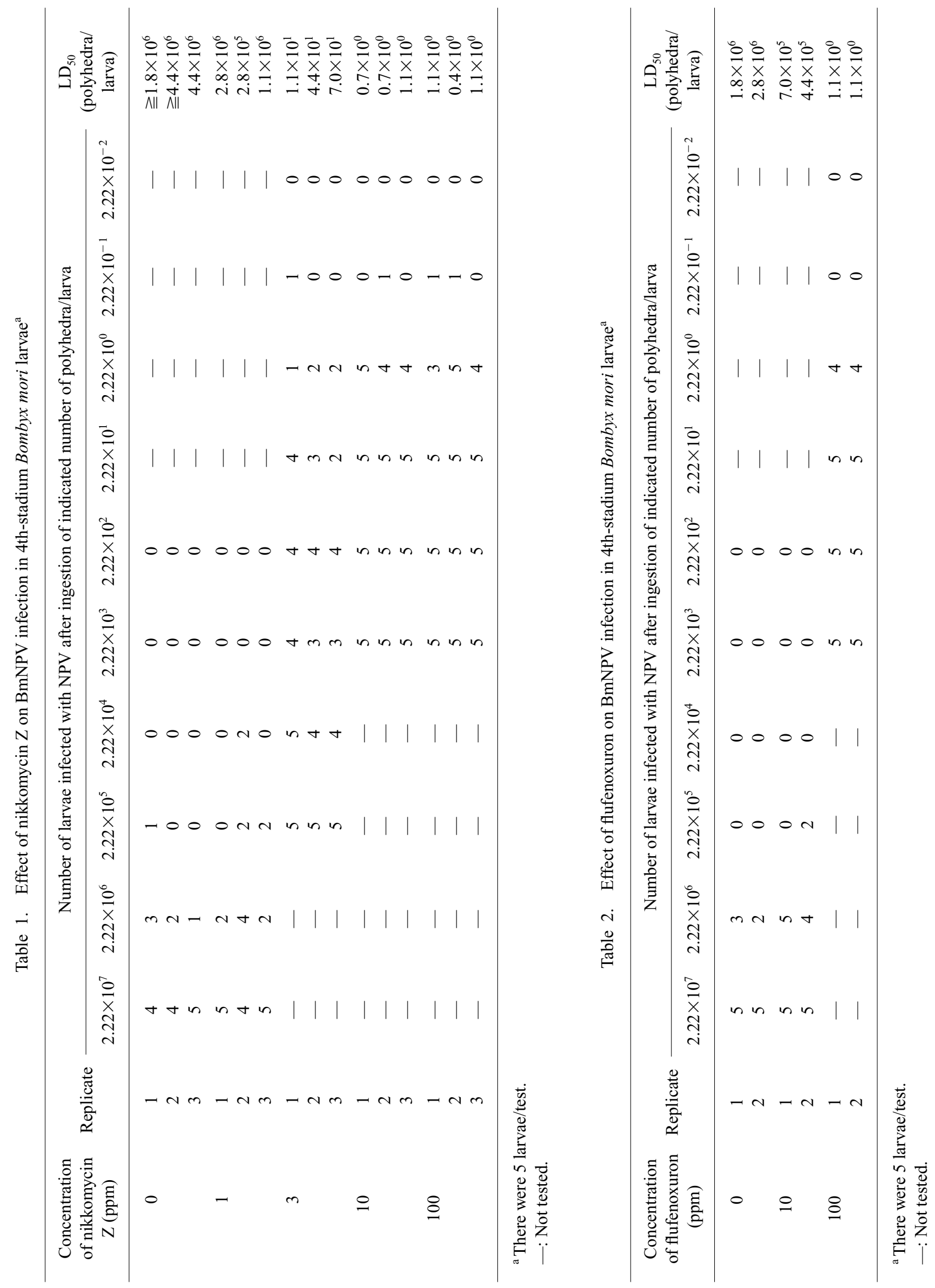
Table 3. Developmental delay of Bombyx mori larvae ingesting $10 \mathrm{ppm}$ nikkomycin $\mathrm{Z}$

\begin{tabular}{|c|c|c|c|c|}
\hline $\begin{array}{l}\text { Larval stadium fed } \\
\text { with nikkomycin Z }\end{array}$ & $\begin{array}{l}\text { Duration of exposure } \\
\text { to nikkomycin } Z\end{array}$ & $\begin{array}{c}\text { No. of larvae } \\
\text { used }\end{array}$ & $\begin{array}{l}\text { No. of larvae molting } \\
\text { to the next stadium }\end{array}$ & $\begin{array}{l}\text { Days of the stadium } \\
\text { (average } \pm \text { SD) }\end{array}$ \\
\hline \multirow[t]{5}{*}{ Third } & $0 \mathrm{~h}$ & 10 & 10 & $4.3 \pm 0.5$ \\
\hline & 24 & 10 & 10 & $\begin{array}{l}5.7 \pm 0.5=p<0.01 \\
p 001<n<0.05\end{array}$ \\
\hline & 72 & 10 & 10 & $6.5 \pm 0.5=0.01<p<0.05$ \\
\hline & 120 & 10 & 10 & $7.1 \pm 0.3=0.01<p<0.05$ \\
\hline & Throughout 3rd stadium & 10 & 10 & $7.5 \pm 0.5 \longrightarrow p>0.05$ \\
\hline \multirow[t]{4}{*}{ Fourth } & $0 \mathrm{~h}$ & 10 & 10 & $5.3 \pm 0.5 \longrightarrow n<001$ \\
\hline & 24 & 10 & 10 & $6.5 \pm 0.5=p<0.01$ \\
\hline & 72 & 10 & 10 & $7.4 \pm 1.0=0.01<p<0.05$ \\
\hline & 120 & 10 & 10 & $7.8 \pm 0.6 \longrightarrow p>0.05$ \\
\hline
\end{tabular}

${ }^{a}$ Pairs of neighboring data were analyzed.

\section{Effect of nikkomycin $Z$ on the development of the silkworm}

Nikkomycin $\mathrm{Z}$ did not prevent molting of the silkworm at $10 \mathrm{ppm}$. All the 3rd- and 4th-stadium larvae ingesting nikkomycin $\mathrm{Z}$ developed to the 4 th- and 5th-stadium respectively (Table 3 ). The data were arranged in order of increasing exposure time of larvae to nikkomycin $\mathrm{Z}$ and the pairs of neighboring results were statistically analysed by a Mann-Whitney $U$-test. In most cases, the silkworm required a longer period to develop to the next stadium as the exposure time to nikkomycin $\mathrm{Z}$ increased. No significant difference was detected for the pairs of $120 \mathrm{~h}$ and throughout the 3rd-stadium and $72 \mathrm{~h}$ and $120 \mathrm{~h}$ of 4 th-stadium larvae (Table 3 ).

\section{DISCUSSION}

It is assumed that nikkomycin $\mathrm{Z}$ interfered with chitin synthesis in the peritrophic membrane producing cells, resulting in the disruption of the membrane and the disappearance of its defensive function, leading to an increase in sensitivity to viral infection. Nikkomycin $Z$ itself or its modified derivatives will serve as synergists of viral pesticides.

Many chemicals were reported to promote viral infection (see Goto, 1999). Among such chemicals, fluorescent brightener 28 has been most extensively studied (Shapiro and Robertson, 1992; Li and Otvos, 1999; Wang and Granados, 2000). Fluorescent brightener 28 has been used at a concentration of about $1 \%$ in the inocula of polyhedral suspension for satisfactory infectious enhancement. Arakawa (2002) showed that flufenoxuron, an insect growth regulator, that inhibited insect molting promoted BmNPV infection only when this chemical was dissolved in acetone and administered to the silkworm B. mori perorally. Flufenoxuron that was incorporated into the diet as a powder form did not exert such an effect. Acetone-dissolved flufenoxuron was effective at concentrations higher than $50 \mathrm{ppm}$ on the 5 th-stadium silkworm larvae (Arakawa, 2002). In the present study, $10 \mathrm{ppm}$ flufenoxuron scarcely promoted viral infection in the 4th-stadium silkworm. On the other hand, nikkomycin $\mathrm{Z}$ was so effective that the silkworm receiving this chemical at $3 \mathrm{ppm}$ and $10 \mathrm{ppm}$ was about $8.5 \times 10^{4}$ and $4.3 \times 10^{6}$ times more sensitive to BmNPV infection than control larvae based on $\mathrm{LD}_{50}$, respectively. Thus, nikkomycin $\mathrm{Z}$ is the most likely candidate for a synergist of viral pesticides to date.

The peritrophic membrane was not observed in the gut of silkworms receiving $10 \mathrm{ppm}$ nikkomycin $Z$. The peritrophic membrane is a barrier to microbes invading the insect perorally (Wang and Granados, 2000). BmNPV-free virions released from the polyhedra by the alkaline gut juice would easily gain access to the midgut cells of the silkworm treated by nikkomycin Z. Nikkomycin Z is an inhibitor of gut and epidermal chitin synthase (Cohen and Casida, 1980; Cohen, 1987; Decker et al., 1991). The peritrophic membrane of insects is a composite structure of chitin and numerous proteins, glycoproteins, and proteoglycans secreted by certain cells in the midgut epithelium (Richards and Richards, 1977; Hopkins and Harper, 2001). Thus, nikkomycin $\mathrm{Z}$ would promote viral infection by destroying the defensive function of the per- 
itrophic membrane in the silkworm by inhibiting gut chitin synthase responsible for the membrane production. Chitin synthase inhibitors are candidates for IGRs. This study and a previous work (Arakawa, 2002) suggest that chemicals inhibiting chitin synthesis in insects should be considered candidates not only for IGRs but also for synergists of viral pesticides.

Nikkomycins are poor insect-control agents because the polar nature of these chemicals restricts their penetration through the hydrophobic insect epicuticle (Cohen, 1987). When ingested, these compounds are likely to be degraded inside the insect alimentary canal. Alternatively, their relatively high molecular weight prevents translocation across membranes of midgut cells (Cohen, 1987). In this study, nikkomycin $\mathrm{Z}$ did not inhibit the molting of the silkworm. On the other hand, Schluter (1982) reported that the Mexican bean beetle (Epilachna varivestis) larvae ingesting nikkomycin that was sprayed on a bean leaf died of failure in molting. The effect of nikkomycins on molting would vary among insect species. Whether or not the effect of nikkomycin $\mathrm{Z}$ to promote viral infection also varies among insect species remains open to future research.

\section{REFERENCES}

Arakawa, T. (2002) Promotion of nucleopolyhedrovirus infection in larvae of the silkworm, Bombyx mori (Lepidoptera: Bombycidae) by flufenoxuron. Appl. Entomol. Zool. 37: 7-11.

Cohen, E. (1987) Chitin biochemistry: synthesis and inhibition. Ann. Rev. Entomol. 32: 71-93.

Cohen, E. and J. E. Casida (1980) Inhibition of Tribolium gut chitin synthetase. Pestic. Biochem. Physiol. 13: 129-136.

Decker, H., H. Zahner, H. Heitsch, W. A. Konig and H. P. Fiedler (1991) Structure-activity relationships of the nikkomycins. J. Gen. Microbiol. 137: 1805-1813.

Finney, D. J. (1964) The Spearman-Karber method. In Statistical Methods in Biological Assay (D. J. Finney ed.). Charles Griffin, London, pp. 524-530.

Goto, C. (1999) Trend of study on enhancement of virus infection for insect pests. Shokubutsu-Boeki 53: 303-307 (in Japanese).

Hopkins, T. L. and M. S. Harper (2001) Lepidopteran peritrophic membranes and effects of dietary wheat germ agglutinin on their formation and structure. Arch. Insect Biochem. Physiol. 47: 100-109.

Lee, S. A., B. S. Clarke, D. W. Jenner and F. A. Williamson (1990) Cytochemical demonstration of the effects of the acylureas flufenoxuron and diflubenzuron on the incorporation of chitin into insect cuticle. Pestic. Sci. 28: 367-375.

Li, S. Y. and I. S. Otvos (1999) Optical brighteners enhance activity of a nuclear polyhedrosis virus against western spruce budworm (Lepidoptera: Tortricidae). J. Econ. Entomol. 92: 335-339.

Okada, M. (1994) Present status and prospect of microbial pest control. Shokubutsu-Boeki 48: 449-454 (in Japanese).

Richards, A. G. and A. P. Richards (1977) The peritrophic membranes of insects. Annu. Rev. Entomol. 22: 219-240.

Sato, T. (1985) Investigation of the present status of microbial control in the United States-An observation report. Shokubutsu-Boeki 39: 53-56 (in Japanese).

Schluter, U. (1982) Ultrastructural evidence for inhibition of chitin synthesis by nikkomycin. Roux Arch. Dev. Biol. 191: 205-207.

Shapiro, M. and J. L. Robertson (1992) Enhancement of gypsy moth (Lepidoptera: Lymantriidae) baculovirus activity by optical brighteners. J. Econ. Entomol. 85: 1120-1124.

Shapiro, M. and J. L. Vaughn (1995) Enhancement in activity of homologous and heterologous baculoviruses infectious to cotton bollworm (Lepidoptera: Noctuidae) by an optical brightener. J. Econ. Entomol. 88: 265-269.

Shieh, T. R. (1989) Industrial production of viral pesticides. Adv. Virus Res. 36: 315-343.

Wang, P. and R. R. Granados (2000) Calcoflour disrupts the midgut defense system in insects. Insect Biochem. Mol. Biol. 30: 135-143. 